\title{
Geometria nas licenciaturas em Matemática: um panorama a partir de Projetos Pedagógicos de
}

\section{Cursos}

\author{
Dienifer da Luz Ferner 1 \\ Maria Arlita da Silveira Soares ${ }^{2}$ \\ Rita de Cássia Pistóia Mariani ${ }^{3}$
}

\begin{abstract}
RESUMO
Diante da importância do desenvolvimento de conceitos geométricos na formação inicial de professores, esta pesquisa objetiva identificar indícios sobre a Geometria, em especial, a Geometria Espacial em Projetos Pedagógicos de Cursos (PPC) presenciais de Matemática Licenciatura em instituições brasileiras. A pesquisa é caracterizada como documental e analisada de modo qualitativo por meio da organização da técnica da Análise de Conteúdo. Os dados permitem afirmar que, em relação aos componentes de Geometria, o campo específico da Geometria Analítica foi o que obteve maior ênfase nos PPC analisados. Quanto a Geometria Espacial, constata-se prevalência da construção axiomática, enfoque na visualização, propostas de trabalho com diferentes representações de objetos geométricos. Contudo, é evidenciada a falta de uma abordagem dos conceitos/conteúdos de Geometria Espacial numa perspectiva didáticametodológica.
\end{abstract}

PALAVRAS-CHAVE: Ensino superior. Conceitos geométricos. Formação inicial.

Geometry in the Mathematics Degree: An Overview from

\footnotetext{
${ }^{1}$ Mestra em Educação Matemática pela Universidade Federal de Santa Maria, Santa Maria, Rio Grande do Sul, Brasil. https://orcid.org/0000-0002-4551-0763.dieniferlferner@gmail.com.

${ }^{2}$ Doutora em Educação nas Ciências pela Universidade Regional do Noroeste do Estado do Rio Grande do Sul, Ijuí, Rio Grande do Sul, Brasil. https://orcid.org/0000-0001-5159-8653.arlitasoares@gmail.com.

3 Doutora em Educação Matemática pela Pontifícia Universidade Católica, São Paulo, São Paulo, Brasil. https://orcid.org/0000-0002-8202-8351.rcpmariani@yahoo.com.br.
} 


\title{
Pedagogical Projects of Courses
}

\begin{abstract}
Given the importance of the development of geometric concepts in the initial teacher education, this research aims to identify evidence on Geometry, in particular, Spatial Geometry in Pedagogical Course Projects (PPC) of Mathematics Degree in Brazilian institutions. The research is characterized as documentary and analyzed in a qualitative way through the organization of the Content Analysis technique. The data allow us to affirm that, in relation to the components of Geometry, the specific field of Analytical Geometry was the one that got more emphasis in the analyzed PPC. As for Spatial Geometry, there is a prevalence of axiomatic construction, focusing on visualizing work proposals with different representations of geometric objects. However, it is evident the lack of an approach to the concepts/contents of Spatial Geometry in a didacticmethodological perspective.
\end{abstract}

KEYWORDS: University education. Geometric concepts. Initial formation.

Grados de Geometría en Matemáticas: Una visión general de los proyectos pedagógicos de los cursos

\section{RESUMEN}

Dada la importancia del desarrollo de conceptos geométricos en la formación inicial del profesorado, esta investigación tiene como objetivo identificar evidencia sobre Geometría, en particular, Geometría Espacial en Proyectos de Curso Pedagógico (PPC) de Grado en Matemáticas en instituciones brasileñas. La investigación se caracteriza por ser documental y analizada de forma cualitativa a través de la organización de la técnica de Análisis de Contenido. Los datos nos permiten afirmar que, en relación con los componentes de la geometría, el campo específico de la geometría analítica fue el que recibió más énfasis en el PPC analizado. En cuanto a la geometría espacial, prevalece la construcción axiomática, centrándose en visualizar propuestas de trabajo con diferentes representaciones de objetos geométricos. Sin embargo, es evidente la falta de un enfoque de los conceptos/contenidos de la Geometría Espacial en una perspectiva didáctico-metodológica. 
PALABRAS CLAVE: Enseñanza superior. Conceptos Geométricos.

Formación inicial.

\section{Introdução}

A aprendizagem de conceitos geométricos é apontada como importante por pesquisadores (PAVANELLO, 1993; FLORES, 1997; PAVANELLO; ANDRADE, 2002; DUVAL, 2004; 2011; SENA; DORNELES, 2013; LOVIS; FRANCO, 2015; SANTOS; OLIVEIRA, 2017; SANCHEZ, 2018) e propostas curriculares (BRASIL, 2002a; 2002b; 2018; SBEM, 2003; 2013), pois possibilita aos estudantes o desenvolvimento de um tipo de raciocínio que permite compreender, descrever e representar o mundo em que vivem.

Segundo Pavanello (2004, p. 4), o campo da Geometria está diretamente relacionado ao "[...] desenvolvimento da capacidade de abstrair, generalizar, projetar, transcender o que é imediatamente sensível". O desenvolvimento dessas capacidades requer que o processo de ensino e aprendizagem esteja voltado à construção de instrumentos para resolução de problemas do cotidiano, de outras áreas do conhecimento ou da própria Matemática. Além disso, destaca-se o importante papel que "o uso das diversas representações matemáticas e das suas inter-relações podem constituir no desenvolvimento do raciocínio geométrico" (SANTOS; OLIVEIRA, 2017, p. 7).

A presente investigação emerge a partir de discussões realizadas no grupo de pesquisa EMgep ${ }^{4}$ sobre o processo de ensino e aprendizagem de Matemática, em particular, de Geometria, bem como de estudos correlatos sistematizados por Pavanello (1993), Pavanello e Andrade (2002) e, Lovis e Franco (2015) que, a mais de duas décadas, apontam dificuldades na aquisição de conceitos geométricos por professores da Educação Básica. Além

\footnotetext{
${ }^{4}$ Educação Matemática: grupo de estudos e pesquisas/UFSM.
} 
dos mapeamentos acerca do processo de ensino e aprendizagem de Geometria realizados por Sena e Dorneles (2013) e Sanchez (2018).

Dentre as pesquisas mencionadas anteriormente, os resultados do estudo de Lovis e Franco (2015), desenvolvido com um grupo de professores de Matemática, apontam indícios das dificuldades para ensinar conceitos geométricos na Educação Básica. Os pesquisadores constataram que nem todos os professores tiveram a oportunidade de cursar um componente curricular de Geometria Euclidiana durante a graduação, ou de participar de discussões sobre metodologias e/ou materiais específicos para o ensino e aprendizagem desse campo.

Sena e Dorneles (2013), a partir de uma busca no Banco de Teses e Dissertações da CAPES ${ }^{5}$, no período de 1991 a 2011, identificaram 101 teses referentes a conceitos geométricos. As investigadoras verificaram que as pesquisas relacionadas a formação inicial de professores de Matemática, nesta área, representam cerca de $13 \%$ do total. Ainda, destacam que os trabalhos identificados neste nível de ensino demonstram “[...] a fragilidade no conhecimento geométrico dos alunos, revelando a ausência de conteúdos fundamentais para estudantes no ensino superior" (SENA; DORNELES, 2013, p. 147).

Sanchez (2018) apresenta um recorte temporal, de 2007 a 2017, de pesquisas brasileiras em programas de pós-graduação stricto sensu na área da Educação Matemática na região sudeste ${ }^{6}$ do Brasil referentes a Geometria Espacial. A partir de uma busca no Banco de Teses e Dissertações da CAPES foram identificadas 14 pesquisas, sendo que cinco delas envolviam estudantes de Ensino Médio, e apenas uma tomava como campo a formação inicial de professores de Matemática. Destaca-se também que a maioria das pesquisas identificadas por Sena e Dorneles (2013) e Sanchez (2018) abordou a utilização de recursos de tecnologia da informação e comunicação no processo de ensino e aprendizagem de Geometria.

\footnotetext{
${ }^{5}$ Coordenação de Aperfeiçoamento de Pessoal de Nível Superior.

${ }^{6}$ Região na qual foi localizada o maior número de programas na área de Educação Matemática.
} 
Esses dados evidenciam a necessidade da produção de mais pesquisas sobre o ensino e aprendizagem de Geometria em cursos de Matemática Licenciatura. Assim, esta pesquisa tem como objetivo identificar indícios sobre a Geometria, em especial, a Geometria Espacial em Projetos Pedagógicos de Cursos (PPC) de Matemática Licenciatura.

\section{A Geometria nos cursos de Matemática Licenciatura: alguns entendimentos}

O debate sobre o currículo dos cursos de Matemática Licenciatura, no Brasil, ocupa considerável espaço de discussão nos meios acadêmicos, intensificado com a publicação das Diretrizes Curriculares Nacionais (DCN), Parecer CNE/CP 9/2001 (BRASIL, 2002a). As DCN expõem um conjunto de princípios, fundamentos e procedimentos a serem observados na organização institucional e curricular de cada estabelecimento de Ensino Superior. Essas ideias são complementadas por documentos produzidos pela Sociedade Brasileira de Educação Matemática (SBEM) e a Sociedade Brasileira de Matemática (SBM) ora em parceria ora separados, bem como por resultados de pesquisas na área da Educação Matemática.

Os documentos supracitados mencionam que conteúdos abordados nos componentes curriculares de Geometria, Cálculo, Análise, Álgebra, por exemplo, precisam ser considerados pelos cursos de formação de professores como conteúdos ampliadores do conhecimento matemático. Para tal, é preciso analisar o aspecto formal da Matemática e os aspectos teórico-metodológicos, pois os conceitos/conteúdos desses componentes

[...] devem [...] possibilitar, [...], conhecimento amplo, consistente e articulado da Matemática, [enfatizando] aspectos de sua construção histórica, suas aplicações [...], os principais métodos utilizados [...] ao longo dos tempos, os avanços e os desafios atuais dessa área de conhecimento. (SBEM, 2003, p. 6). 
Nesta perspectiva, os conceitos/conteúdos que serão abordados pelo futuro professor, por exemplo, os relacionados à Geometria na Educação Básica, precisam "[...] ser aprofundados nos seus aspectos epistemológicos e históricos e tratados de modo articulado com conteúdos mais complexos da Matemática e também com suas didáticas específicas" (SBEM, 2003, p. 6).

Para que o futuro professor desenvolva atividades que propiciem ao estudante da Educação Básica construir seu próprio conhecimento, é necessário que os cursos de formação inicial sejam organizados, de modo a fornecer subsídios para essa construção. Para tal, entende-se que os componentes curriculares que abordam a matemática escolar, sob a ótica mais avançada do Ensino Superior, podem e devem se preocupar com a ampliação, bem como com a ressignificação do conhecimento matemático, enriquecendo a formação do licenciando "ao explicitar o conteúdo específico de matemática necessário à prática docente, equilibrando com o conhecimento de cunho pedagógico constante em seu currículo" (SBEM, 2013, p. 18). Assim, nos componentes curriculares de Geometria, Cálculo, Análise, Álgebra, entre outros, não se ensina apenas conceitos e procedimentos matemáticos, mas se auxilia e influencia a maneira como o futuro professor compreende "o que é ser professor", isto é, "um modo de conceber e estabelecer relações com o mundo e com a matemática e seu ensino" (FIORENTINI, 2005, p. 111).

Em relação ao ensino e aprendizagem de Geometria nos cursos de licenciatura, entende-se que é preciso construir espaços-tempo para que os acadêmicos se apropriem dos conceitos da Geometria e possam percebê-la nas suas principais dimensões: "como visualização, construção e medida de figuras; como estudo do mundo físico; como veículo para representar outros conceitos matemáticos; como um exemplo de um sistema matemático (axiomático)" (SBEM, 2003, p. 8).

Conforme Pavanello e Andrade (2002, p. 83), o ensino de Geometria na licenciatura "não pode se caracterizar como revisão de matéria, porque, de fato, não é uma questão de 'ver novamente', aquilo que já foi ensinado. Pelo 
contrário, muitos estudantes estarão aprendendo pela primeira vez." Além disso, a construção axiomática da Geometria, fundamental na formação do professor, "não pode acontecer desligada de um trabalho de construção de conceitos através de atividades, pois esta construção e a axiomática não são independentes" (PAVANELLO; ANDRADE, 2002, p. 83).

As pesquisadoras, ainda, sugerem a organização de componentes curriculares que explorem os conceitos geométricos numa perspectiva experimental e sejam discutidos recursos didático-metodológicos envolvidos no processo de ensino e aprendizagem. E, simultaneamente, sejam ofertados compomentes direcionados a construção axiomática da Geometria, tendo por base as discussões feitas nos componentes com viés experimental. "Configurar-se-ia, assim, uma construção nível a nível, a experimentação servindo de base a axiomatização e esta oferecendo subsídios para novas atividades [experimentais], num processo 'em espiral”' (PAVANELLO; ANDRADE, 2002, p. 83).

Nesta perspectiva, os conhecimentos de Geometria serão abordados na formação inicial do professor de modo a potencializar o "desenvolvimento de uma forma de pensar que contribua para a problematização e modelagem do espaço em que vivemos, integrando intuição e rigor num movimento constante entre experimentação e dedução" (BONINI; DRICK; BARRA, 2018, p. 157). Além disso, a importância da demonstração para o ensino e aprendizagem da Matemática, em particular, da Geometria, ganhará destaque.

Entende-se que o trabalho articulado entre a Geometria experimental e a axiomática pode ser enriquecido com o uso de software de Geometria Dinâmica. Segundo Duval (2011), os software estão cada vez mais precisos para a representação de objetos matemáticos, em particular, figuras geométricas. Elas podem ser deslocadas, rodadas, estendidas a partir de um ponto, etc. "Esse aspecto 'dinâmico' é apenas uma consequência da potência ilimitada do tratamento" (DUVAL, 2011, p. 137). A aceleração dos tratamentos é proporcionada pelas ferramentas de manipulação direta (mudar a posição da figura, sem modificá-la) e arrastamento (mudar o 
comprimento dos lados da figura, reconfigurá-la).

As figuras geométricas apresentadas pelos software ganham uma "confiabilidade e uma objetividade que permitem efetuar verificações e observações" (DUVAL, 2011, p. 84) que contribuem na visualização e no raciocínio. Destaca-se que, a visualização é entendida como "a habilidade de representar, transformar, gerar, comunicar, documentar, e refletir sobre a informação visual” (FLORES, 1997, p. 5). Assim, a visualização é uma atividade cognitiva intrinsecamente semiótica e não apenas de percepção, pois proporciona a identificação das relações entre os elementos que organizam a figura (DUVAL, 2004). O raciocínio, na perspectiva de Duval (2011), é o processo que conduz a elaboração de demonstrações, a base da compreensão em Matemática, em particular, em Geometria.

Cabe destacar que, ao tratar da Geometria, nos cursos de formação de professores, é preciso buscar as interfaces da Geometria Euclidiana com a Geometria Analítica, Trigonometria, Desenho Geométrico, Geometria Descritiva, Geometria Diferencial, Cálculo, entre outos. Também, é importante ir além da Geometria Euclidiana, ou seja, discutir aspectos de Geometrias Não Euclidianas (PAVANELLO; ANDRADE, 2002; SBEM, 2003, 2013). O estudo de Geometrias não Euclidinas auxilia o futuro professor a compreender de que forma o tratamento axiomático evolui e contribui com o desenvolvimento da própria Matemática (SBEM, 2013).

Desta forma, reconhece-se que os conceitos/conteúdos geométricos devem ser abordados de forma articulada juntamente com os distintos componentes curriculares de um curso de Matemática Licenciatura. Ressaltase que, para esta articulação é recomendado o uso de recursos didáticos que busquem contribuir para o entendimento dos estudantes, bem como mobilizar teorias que explorem o processo de construção do raciocínio geométrico.

\section{Escolhas metodológicas}

Optou-se por uma abordagem qualitativa, pois esta privilegia “[...] 
procedimentos descritivos à medida em que sua visão de conhecimento explicitamente admite a interferência subjetiva, o conhecimento como compreensão que é sempre contingente, negociada e não é verdade rígida" (BORBA, 2004, p. 2). Assim, os dados estão apresentados de forma descritiva, mas isto, conforme Borba (2004), não exclui qualquer dado quantitativo.

Considerando que há diferentes modalidades na pesquisa qualitativa, definiu-se a análise documental para subsidiar esta investigação, pois os dados utilizados são Projetos Pedagógicos de Cursos (PPC) de Matemática Licenciatura. Para a análise dos dados, quanto aos procedimentos, a pesquisa busca inspiração em pressupostos da Análise de Conteúdo. Para Bardin (2011, p. 48), esta é "um conjunto de técnicas de análise das comunicações", com objetivo de obter indicadores que possibilitem a "inferência de conhecimentos relativos às condições de produção/recepção" das mensagens.

O conjunto de técnicas de análise é organizado em três etapas: préanálise, exploração do material e tratamentos dos resultados e interpretações.

A pré-análise é basicamente a organização da pesquisa, etapa que compreende a formulação dos objetivos, leitura "flutuante", escolha dos documentos a serem analisados e elaboração das categorias de análise, não necessariamente nesta ordem. Nesta etapa, foram identificados os Projetos Pedagógicos de Cursos presenciais de Matemática Licenciatura em instituições brasileiras que fossem gratuitos e estivessem em atividade. Para tanto, a página digital do e-MEC7 ${ }^{7}$, que contém o cadastro das instituições de Ensino Superior e seus respectivos cursos, foi acessada. Entre os dias 28 de junho e 09 de julho do ano de 2018, foi realizada uma "Consulta interativa"8 em cada uma das unidades federativas (estados e distrito federal) brasileiras, nestas buscou-se por cursos presenciais de Matemática Licencitura em atividade e gratuitos.

A etapa de exploração do material baseia-se na análise e produção de

\footnotetext{
${ }^{7}$ Página organizada pelo Ministério da Educação, na qual instituições de educação superior realizam o credenciamento, buscam autorização, reconhecimento e renovação de reconhecimento de cursos.

${ }^{8}$ Opção disponibilizada pelo site.
} 
dados. Assim, para cada curso identificado, coletou-se, quando possível, as seguintes informações: data de criação; localização do curso; instituição de ensino; busca pelo PPC; componentes curriculares referentes a Geometria. Com essas informações foram organizados quadros de modo a facilitar a compreensão dos dados para então serem discutidos na etapa de tratamento dos resultados e interpretações. Etapa esta que consiste em tratar dados obtidos de modo a se tornarem significativos e válidos e que será apresentada na seção seguinte.

\section{Tratamento dos resultados e interpretações}

Nesta etapa, buscou-se investigar projetos pedagógicos de cursos presenciais de Matemática Licenciatura em instituições públicas brasileiras que estivessem em atividade para então identificar alguns aspectos sobre a aborgadem da Geometria, em especial, a Geometria Espacial.

Foram identificados 329 cursos vinculados a 127 instituições de Ensino Superior, distribuídas em todas unidades federativas brasileiras. Salienta-se que a criação dos cursos de formação de professores de Matemática foi identificada até o ano consultado, ou seja, 2018. O ápice de abertura destes cursos foi entre os anos de 2009 e 2011, com o início de 85 cursos, os quais representam aproximadamente $26 \%$ do total mapeado, sendo em sua maioria (63 cursos) ofertados por instituições federais de ensino.

$O$ resultado apresentado pode ter sido influenciado pelo decreto $n^{\circ}$ 6.096, de 24 de abril de 2007, o qual instituiu o Programa de Apoio a Planos de Reestruturação e Expansão das Universidades Federais (REUNI), na busca pela ampliação do acesso e a permanência na Educação Superior, em outras palavras, o aumento de vagas e a criação de novos cursos deste nível de ensino. O Gráfico 1 apresenta a distribuição, por regiões brasileiras, das instituições e cursos mapeados. 
GRÁFICO 1: Instituições e cursos mapeados em unidades federativas brasileiras

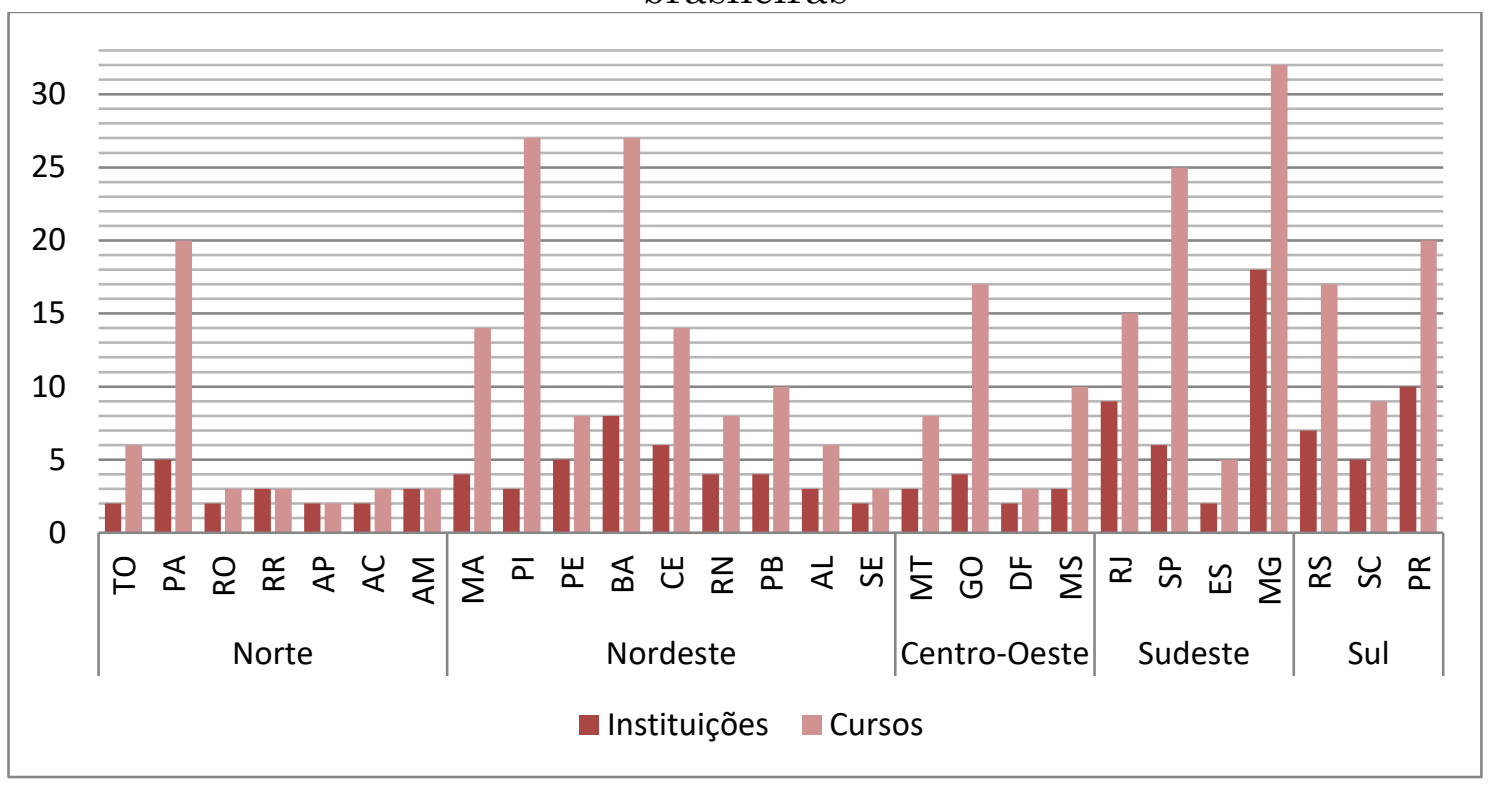

Fonte: Dados da pesquisa.

A região sudeste, apesar de ser a maior do país em relação à quantidade de habitantes $(41,9 \%)^{9}$, apresenta, aproximadamente, 23,7\% dos cursos mapeados. Em contrapartida, a região nordeste oferta 35,9\% cursos de Matemática Licenciatura gratuitamente de forma presencial, mesmo esta não sendo a maior em área territorial e com uma população de 27,6\% de habitantes. Cabe destacar que, a metade dos cursos localizados na região nordeste são oferecidos por instituições federais de ensino. Diante desse resultado, destaca-se que dentre 329 cursos mapeados, 205 são ofertados por instituições federais, 121 por instituições estaduais e três por instituições municipais.

$\mathrm{Na}$ busca por refinar os dados apresentados, optou-se por investigar os cursos de Matemática Licenciatura presenciais oferecidos por instituições federais, visto que estes representam, aproximadamente, 62,3\% do total, são mantidos pelo mesmo órgão público, e estão localizados, ao menos um, em cada unidade federativa. Para tanto, acessou-se os sites dos cursos

\footnotetext{
${ }^{9}$ Dados estimados sobre a população brasileira apresentados no site do Instituto Brasileiro de Geografia e Estatística IBGE, acessado pelo link: <https://www.ibge.gov.br/estatisticas-novoportal/por-cidade-estadoestatisticas.html?t=destaques\&c=Brasil $>$ em agosto de 2018 .
} 
selecionados, na busca de seus Projetos Pedagógicos de Curso (PPC), visto que são documentos públicos e devem estar disponíveis para acesso. Constatouse, dentre os 205 cursos mapeados anteriormente, um total de 113 PPC disponíveis de forma online no site dos cursos, estes dados estão organizados no Gráfico 2, segundo suas respectivas unidades federativas.

Gráfico 2: Organização por unidades federativas dos cursos de Matemática Licenciatura presenciais em atividade ofertados por instituições federais

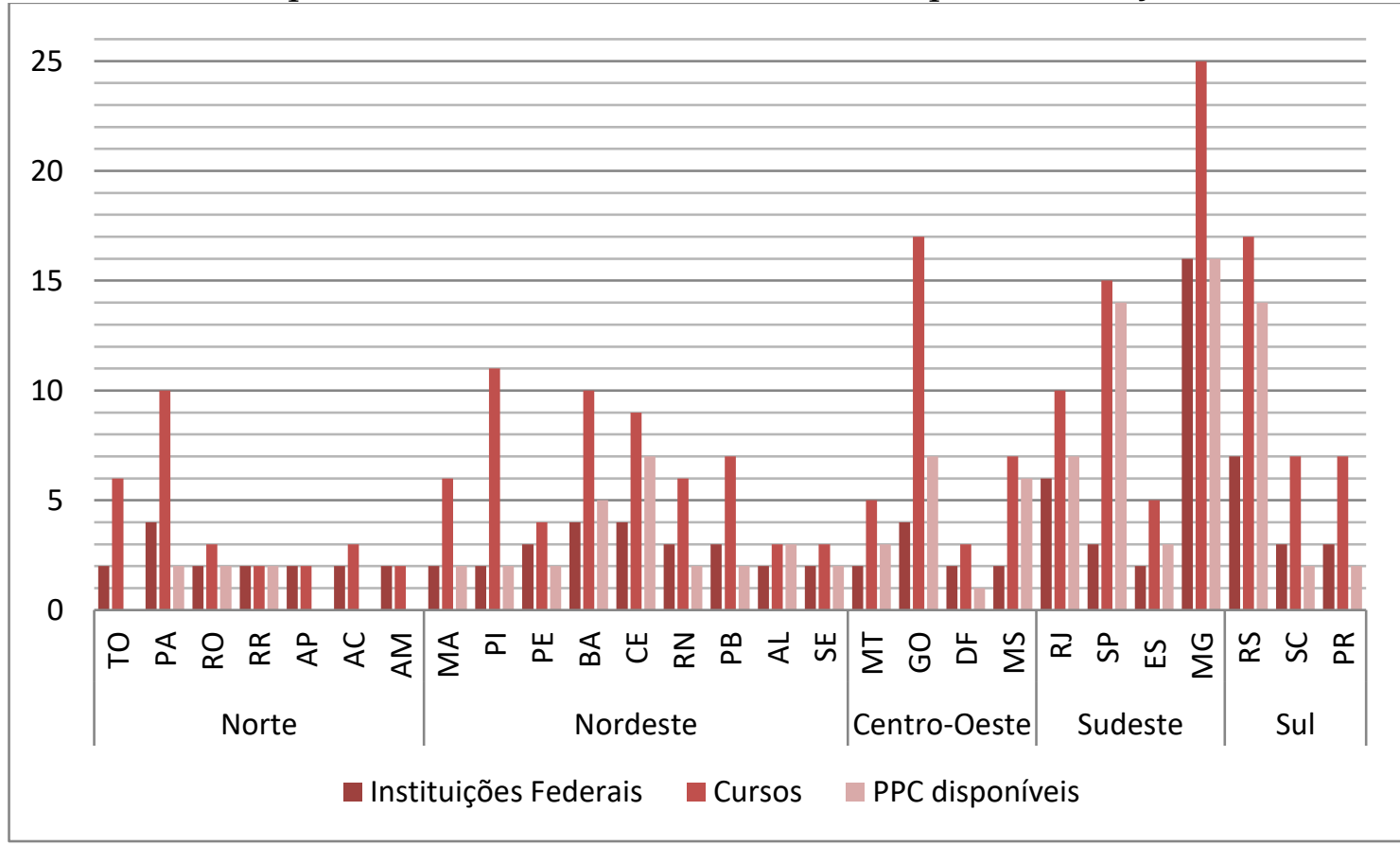

Fonte: Dados da pesquisa.

As regiões centro-oeste, sul e norte possuem, respectivamente, 15,6\%, $15,1 \%$ e $13,7 \%$ dos cursos ofertados por instituições federais. No entanto, mais uma vez, as regiões brasileiras que se destacam são a sudeste e nordeste, com, respectivamente, a maior quantidade de instituições federais, 27,7\% do total, e a maioria dos cursos de formação inicial de professores de Matemática, $28,8 \%$ na totalidade.

Dentre os 59 cursos identificados na região nordeste, nove são oferecidos por Institutos Federais de Educação, Ciência e Tecnologia (IF) que estão localizados com pelo menos uma unidade em cada estado pertencente a esta região. Ao todo constatou-se 81 institutos federais que ofertam cursos de 
formação inicial de professores de Matemática no Brasil. Dessas 32 são IF, cerca de 39,5\%, e os estados de Goiás, Minas Gerais, Rio de Janeiro e Rio Grande do Sul, possuem mais de uma instituição como esta.

Evidencia-se que apenas os estados do Paraná e Mato Grosso do Sul não possuem IF que ofertam curso de Matemática Licenciatura. Uma hipótese a ser estabelecida para a não existência de um curso de formação inicial de professores de Matemática no IF de Mato Grosso do Sul, é que a Universidade Estadual e a Universidade Federal deste estado, juntas oferecem nove cursos, dentre os quais sete são ofertados nas mesmas cidades em que os institutos possuem sede.

O estado de Minas Gerais abrange 16 instituições federais que ofertam cursos de formação inicial de professores de Matemática de forma presencial. Este fato resulta no maior número de cursos oferecidos em uma unidade federativa brasileira, 25 cursos ao total, distribuídos em 11 universidades e cinco IF.

Salienta-se que 16 dos cursos mapeados no estado de Minas Gerais possuem seus PPC disponíveis para acesso de forma online em seus sites. Este dado, juntamente com os 14 cursos do estado de São Paulo, contribuíram para que a região sudeste seja a que apresentou a maior quantidade de cursos Matemática Licenciatura, ofertados presencialmente por instituições federais, com seus PPC disponíveis em seus sites, com a representatividade de $35,7 \%$.

O estado do Rio Grande do Sul encontra-se após o estado de Minas Gerais em quantidade de instituições federais mapeadas e de cursos de Licenciatura em Matemática, ofertados de forma presencial. Desta forma, é o segundo estado brasileiro a proporcionar a formação de novos professores nesta área de ensino.

Dentre os cursos de formação inicial de professores de Matemática ofertados em instituições federais, foi identificado um total de 55,1\% dos PPC. Estes documentos objetivam apresentar o curso e sua organização, expondo, em sua maioria, itens como: dados de identificação do curso; objetivos; perfil 
do egresso; campo de atuação profissional; corpo docente; organização curricular, entre outros.

Para prosseguir com a análise, recorreu-se aos PPC que apresentam ementa/objetivos para cada um dos componentes curriculares ofertados durante o curso. Desta forma, recorreu-se a 95 PPC, pois 18 dos cursos mapeados anteriormente não cumpriram com o requisito estabelecido.

$\mathrm{Na}$ busca por identificar os componentes específicos da Matemática e os de ensino e aprendizagem que apresentassem algum conceito/conteúdo relacionado à Geometria Espacial, optou-se por utilizar a ferramenta de pesquisa disponibilizada por programas leitores de arquivos em formato $p d f$. Nesta ferramenta aplicou-se os descritores: "geometri", o qual associou termos como geometria e geométrico(s); "espaço e forma" e "grandezas e medidas", por se tratarem de eixos/blocos de conteúdos empregados pelos PCN e BNCC que envolvem conceitos/conteúdos relacionados ao campo da Geometria. Cabe destacar que, a busca com os descritores foi realizada no nome, ementa e objetivos dos componentes curriculares contidos nos PPC.

Localizou-se 645 componentes curriculares específicos da Matemática (Quadro 1), os quais foram categorizados conforme os conceitos/conteúdos que estavam propostos em sua ementa, como: Desenho Geométrico; Desenho Geométrico e Geometria Descritiva; Desenho Geométrico e Geometria Plana; Geometria Analítica; Geometria Descritiva; Geometria Diferencial; Geometria Espacial; Geometria Fractal; Geometrias Não Euclidianas; Geometria Plana; Geometria Plana e Espacial; Outros. Destaca-se que esta última categoria, "Outros", abrange componentes curriculares que possuem como objetivo explorar distintos conceitos/conteúdos específicos da Matemática ${ }^{10}$, os quais complementam a formação inicial de professores desta área.

\footnotetext{
${ }^{10}$ Matemática Básica; Variáveis Complexas; Física; Álgebra Linear; Matemática Discreta; Cálculo Diferencial e Integral; Libras; Probabilidade e Estatística; Trigonometria; entre outras.
} 
QUADRO 1: Organização dos componentes curriculares mapeados com a utilização dos descritores

\begin{tabular}{|c|c|c|c|c|}
\hline \multicolumn{2}{|c|}{ Componentes Curriculares } & Obrigatórios & Optativos & Total \\
\hline \multirow{13}{*}{$\begin{array}{l}\text { Específicos da } \\
\text { Matemática }\end{array}$} & Desenho Geométrico & 42 & 9 & 51 \\
\hline & $\begin{array}{l}\text { Desenho Geométrico e } \\
\text { Geometria Descritiva }\end{array}$ & 6 & 1 & 7 \\
\hline & $\begin{array}{c}\text { Desenho Geométrico e } \\
\text { Geometria Plana }\end{array}$ & 10 & 0 & 10 \\
\hline & Geometria Analítica & 120 & 0 & 120 \\
\hline & Geometria Descritiva & 4 & 1 & 5 \\
\hline & Geometria Diferencial & 4 & 15 & 19 \\
\hline & Geometria Dinâmica & 2 & 0 & 2 \\
\hline & Geometria Espacial & 72 & 0 & 72 \\
\hline & Geometria Fractal & 0 & 1 & 1 \\
\hline & $\begin{array}{c}\text { Geometrias Não } \\
\text { Euclidianas }\end{array}$ & 16 & 4 & 20 \\
\hline & Geometria Plana & 80 & 1 & 81 \\
\hline & $\begin{array}{c}\text { Geometria Plana e } \\
\text { Espacial }\end{array}$ & 19 & 0 & 19 \\
\hline & Outros & 202 & 36 & 238 \\
\hline Ensin & Aprendizagem & 90 & 8 & 98 \\
\hline
\end{tabular}

Fonte: Dados da pesquisa.

Os componentes curriculares classificados como "Outros", foram mapeados por, na maioria dos casos, apresentar em sua ementa o descritor "geometri", por exemplo, em "Cálculo Diferencial e Integral” há em sua ementa a interpretação geométrica de conceitos/conteúdos como: limite, derivada e integral; "Matemática Discreta" que propõe o estudo de Progressões Geométricas; "Libras" apresenta o ensino de sinais básicos e a expansão do vocabulário, dentre os quais estão os conceitos geométricos.

O campo específico da Geometria que obteve maior ênfase nos PPC mapeados foi a Geometria Analítica. Nesta as representações mais utilizadas são as algébricas e gráficas, tendo em vista os conceitos/conteúdos a serem explorados ${ }^{11}$, essa constatação foi realizada diante do exposto em suas ementas e/ou objetivos. São 120 componentes curriculares obrigatórios referentes à Geometria Analítica, distribuídos entre os 95 PPC mapeados. Em outras palavras, 24 cursos ofertam dois componentes curriculares com

\footnotetext{
${ }^{11}$ Geralmente, coordenadas cartesianas, vetores no plano e no espaço, posições relativas entre retas e planos, lugares geométricos, entre outros.
} 
conceitos/conteúdos específicos de Geometria Analítica e o curso oferecido pelo Instituto Federal de Educação, Ciência e Tecnologia Fluminense/RJ, oferta três componentes curriculares obrigatórios referentes a esse campo da Geometria, a saber: Geometria Analítica I (Vetores no Plano, reta no $\mathbb{R}^{2}$, circunferência no $\mathbb{R}^{2}$ ); Geometria Analítica II (elipse, hipérbole, parábola, equações de retas e cônicas em coordenadas polares); Geometria Analítica III (vetores no espaço, plano, reta no $\mathbb{R}^{3}$, superfícies quádricas).

Os estudos de Pavanello e Andrade (2002) e os documentos da SBEM (2003; 2013) salientam a importância de se abordar conceitos/conteúdos das Geometrias Não Euclidianas, no entanto, ao buscá-los nos PPC, verificou-se um total de 20 componentes curriculares nesta área. Este resultado indica que não são todos os cursos que oferecem este tipo de conceitos/conteúdos durante a graduação. $\mathrm{O}$ componente curricular referente a conceitos/conteúdos da Geometria Fractal foi identificado na Universidade Federal do Pampa, Campus Itaqui/RS, de forma optativa. O qual, além de propor o estudo de conceitos/conteúdos deste campo, apresenta a proposta de elaboração de atividades para a inserção desta Geometria na Educação Básica.

A Geometria Dinâmica como componente curricular foi identificada na Universidade Federal do Rio Grande/RS, esta é proposta com carga horária de 90h, distribuídas em dois componentes curriculares obrigatórios que visam explorar conceitos/conteúdos de Geometria Plana e Espacial por meio de ferramentas que tornem a Geometria dinâmica. Entende-se que este componente, juntamente, com os demais ofertados pelo curso contribuem para que a construção axiomática da Geometria aconteça de modo articulado com a construção de conceitos, conforme sugerem Pavanello e Andrade (2002).

A Geometria Diferencial, apesar de apresentar 19 componentes curriculares, 15 destes são ofertados de forma optativa, ou seja, apenas quatro cursos mapeados exploram de forma exclusiva e obrigatória conceitos/conteúdos deste campo da Geometria. Os cursos mencionados são ofertados pelas seguintes instituições de ensino: Instituto Federal de 
Educação, Ciência e Tecnologia Goiano/GO; Universidade Federal de Goiás/GO; Universidade da Integração Internacional da Lusofonia AfroBrasileira/CE; Universidade Federal de Roraima/RR.

A Geometria Descritiva, campo que se destina ao estudo de figuras espaciais sobre o plano, ou seja, figuras $3 \mathrm{D}$ representadas em $2 \mathrm{D}$, mesmo quando aliada ao Desenho Geométrico, foi a menos enfatizada, após a Geometria Fractal e a Geometria Dinâmica, apresentando apenas 12 componentes curriculares distribuídos em 11 instituições federais. Sublinhase que a discussão realizada em aulas referentes à Geometria Descritiva pode estar diretamente relacionada a uma seção de componentes curriculares de Desenho Geométrico. Sendo assim, não se pode concluir que essa não é abordada ao longo do curso de formação quando não mapeada em um componente específico.

Obteve-se 68 componentes curriculares de Desenho Geométrico, reunindo os ofertados juntamente com conceitos/conteúdos de Geometria Descritiva ou Geometria Plana, o que permite concluir que este componente curricular não é oferecido em todos os cursos mapeados. Outro fato que precisa ser evidenciado é o de que, mesmo diante desta informação, não podese afirmar que os conceitos/conteúdos referentes a este campo da Geometria não são trabalhados no decorrer do curso, pois podem estar distribuídos em diferentes componentes curriculares, como, por exemplo, Geometria Plana e/ou Espacial na construção de objetos matemáticos por meio de suas propriedades.

Assuntos específicos da Geometria Plana, os quais foram identificados nas categorias "Desenho Geométrico e Geometria Plana", "Geometria Plana", "Geometria Plana e Espacial", são discutidos em 110 componentes curriculares, distribuídos em 94 instituições federais, isto é, apenas uma instituição da região centro-oeste do Brasil não aborda esse campo da Geometria de forma específica. Salienta-se que esta instituição, em relação a componentes curriculares específicos de conceitos/conteúdos da Geometria, oferta apenas um referente a Geometria Analítica e um de Desenho 
Geométrico.

Os conceitos/conteúdos relacionados à GE foram explorados, de forma específica, em 91 componentes curriculares, nestes foram contabilizados, também, os que estudam conceitos/conteúdos de Geometria Plana de forma conjunta. Sendo distribuídos em 85 cursos de formação inicial de professores, isto é, a GE não é explorada de forma específica em oito dos cursos mapeados, nesta parte da pesquisa. No entanto, há quatro $\operatorname{cursos}^{12}$ que oferecem dois componentes curriculares específicos de GE.

Verificou-se que, aproximadamente, 70,3\% dos componentes mapeados são ofertados no início do curso, ou seja, entre o $1^{\circ}$ e o $3^{\circ}$ semestres. Também, foi possível perceber que, cerca de $49 \%$ dos cursos analisados, apresentam o pré-requisito de um componente curricular de Geometria Plana. Cabe destacar que, nesta apuração percentual, foram desconsiderados os componentes curriculares ofertados no $1^{\circ}$ semestre e os que estão relacionados a conceitos/conteúdos de Geometria Plana.

Diante das ementas verificadas, pôde-se observar que os componentes curriculares referentes à GE abordam, geralmente, assuntos relacionados a posições relativas entre retas, planos e reta e plano, áreas e volumes de sólidos geométricos, geralmente, nesta sequência.

A partir dos objetivos, identificados em 41 componentes curriculares expostos nos PPC referentes a essa área da Geometria, 17 deles enfatizam a abordagem axiomática, isto é, visam o reconhecimento e utilização de axiomas e/ou teoremas para demonstrar resultados da GE. Um exemplo a ser citado é a descrição fornecida por um dos PPC, o qual apresenta como um dos objetivos "[...] aprofundar a capacidade de argumentação matemática a fim de poder verificar a veracidade de afirmações relacionadas ao estudo." (Excerto PPC413). A ação de "calcular áreas e volumes de sólidos geométricos” (Excerto PPC153), também, foi uma das abordagens mencionadas entre os objetivos

\footnotetext{
12 Estes cursos são ofertados pelas seguintes instituições: Instituto Federal de Educação, Ciência e Tecnologia Fluminense/RJ; Instituto Federal de Educação, Ciência e Tecnologia do Espírito Santo, campus Cachoeiro de Itapemirim/ES; Universidade Federal de Viçosa, campus Viçosa/MG; Universidade Federal de Mato Grosso, campus Rondonópolis/MT.

${ }^{13}$ Os fragmentos dos PPC serão apresentados desta forma de modo a não expor a instituição de ensino.
} 
analisados, com um total de sete citações. Sublinha-se que, o estudo da GE não pode limitar-se ao estudo de grandezas e medidas, pois a identificação das propriedades associadas às posições relativas das formas são tão importantes quanto as propriedades métricas para o desenvolvimento do raciocínio geométrico.

Em 10 dos componentes curriculares em que se analisou os objetivos, são propostas discussões sobre a abordagem da GE na Educação Básica, os quais mencionam o fato de refletir sobre e "Compreender o processo de ensino e aprendizagem de Geometria Espacial na educação básica.” (Excerto PPC79). Por se tratar de cursos de Matemática Licenciatura, pode-se pensar que ocorra essa ação, também, em componentes curriculares referentes ao ensino e aprendizagem de conceitos/conteúdos de Geometria. No entanto, entre os 95 PPC analisados, apenas 44,2\% apresentaram algum componente curricular referente a este assunto por meio dos descritores utilizados. Este resultado é preocupante, pois são inúmeras as dificuldades apresentadas tanto por professores como por estudantes de qualquer nível de ensino no estudo de conceitos geométricos (PAVANELLO, 1993; LOVIS; FRANCO, 2015).

Ressalta-se que os conceitos/conteúdos da Educação Básica não podem ser abordados sob uma perspectiva apenas de revisão e/ou ampliação, mas numa perspectiva didático-metodológica. Segundo Pires (2002, p. 56), com base nas DCN, "nos cursos de licenciatura, os conteúdos a serem ensinados na escolaridade básica devem ser tratados de modo articulado com suas didáticas específicas". Em outros termos, é importante que os futuros professores, ao estudarem conceitos geométricos, conheçam os conteúdos propostos no currículo da Educação Básica, por exemplo, na Base Nacional Comum Curricular (BRASIL, 2018) e, também, teorias que buscam explicar o processo de desenvolvimento do raciocínio geométrico, elaboradas por Van Hiele ${ }^{14}$, Duval $(2004,2011)$, entre outros.

Os dados permitem inferir que os cursos não estão enfatizando esse

\footnotetext{
${ }^{14}$ Elaborada pelo casal Dina Van Hiele-Geldof e Pierre Van Hiele que buscaram entender e obter explicação sobre a ruptura entre o ensino da Geometria e sua compreensão.
} 
trabalho de forma articulada. Apesar dos PPC mencionarem a importância de relacionar os conceitos/conteúdos com os abordados na Educação Básica, ao analisar as ementas dos componentes de Geometria, em particular, é notória a ênfase na construção axiomática. Além disso, os componentes curriculares de cunho pedagógico não privilegiam discussões sobre questões específicas do processo de ensino e aprendizagem de conceitos geométricos.

Constatou-se que sete PPC destacam o desenvolvimento da habilidade de visualização de figuras no espaço e/ou em perspectiva em seus componentes curriculares de GE. Em outras palavras, buscam explorar aspectos visuais da GE. Salienta-se que quatro PPC sublinham a abordagem axiomática em conjunto com a necessidade de visualizar, compreendendo que uma ação complementa a outra. Destaca-se que esta relação vem ao encontro das ideias propostas por documentos curriculares e pesquisas na área que orientam a necessidade de articulação entre Geometria experimental e axiomática. Não se pode afirmar que os demais PPC não interpertam desta forma, porém não mencionam de forma explícita esta ação. No entanto, um dos PPC mapeados revela que o objetivo do componente curricular "[...] não é axiomatizar a geometria. Pelo contrário, a intenção é explorar sobremaneira os seus aspectos visuais." (Excerto PPC159).

Ressalta-se que a habilidade de visualizar é evidenciada em documentos curriculares da Educação Básica. Sendo assim, torna-se relevante explorar seu desenvolvimento na formação inicial de professores de Matemática. O termo visualização esta presente na maioria das ementas e/ou objetivos analisados. Contudo, o uso desse termo pode estar associado a criação de novos software de Geometria Dinâmica, os quais prometem contribuir na visualização de objetos matemáticos. Assim, a visualização mencionada nos PPC pode não estar relacionada a perspectiva de Duval (2004, 2011), ou seja, a uma atividade semiótica que vai além do acesso direto as formas (contornos fechados, justapostos, superpostos, separados) que permite identificar as unidades figurais de representação - dimensional (OD, 1D, 2D e 3D) e qualitativa (forma e elementos geométricos) -, bem como 
realizar uma desconstrução dimensional (olhar uma figura nas dimensões inferiores ao que é dada).

As representações dos objetos geométricos no espaço, visando desenvolver a percepção espacial do estudante e relacionando diretamente com o ato de construir os elementos/sólidos, recebem destaque nos objetivos de 11 componentes curriculares de GE. Esse objetivo, em sete de suas menções, vêm acompanhado da utilização de recursos didáticos, como: régua e compasso, software de Geometria Dinâmica e materiais manipuláveis.

Quanto ao uso dos recursos didáticos supracitados, dentre os componentes curriculares de GE, um total de 10, os mencionam em seus objetivos. Por vezes aparecem de forma conjunta, por exemplo, "Investigar e explorar as propriedades gerais dos sólidos geométricos [...] de sua representação em perspectiva ou planificada, por meio de desenho no papel ou com o uso de software aplicativo." (Excerto PPC79), ou de forma separada, mencionando apenas um tipo de representação, por exemplo, "Desenvolver a capacidade do educando de representar, no espaço tridimensional, retas, planos e sólidos geométricos, bem como a manipulação dos mesmos através de materiais concretos." (Excerto PPC4).

Entende-se que, por vezes, a citação da utilização de diferentes representações e o uso de recursos didáticos não é realizada nos objetivos de um componentes curricular, mas estes contribuem fortemente com a compreensão em Geometria.

\section{Conclusão}

O PPC é o documento que expõe a identidade do curso, apresentando sua proposta de formação. Por este motivo é alarmante o fato de que, dentre os cursos mapeados, identificou-se um total de, aproximadamente, $55 \%$ de PPC disponíveis para acesso online e quando verificam-se objetivos e/ou ementas descritas nos documentos a porcentagem reduz-se para $46 \%$ dos cursos. 
Os documentos analisados destacam a necessidade de se articular a Geometria com outros componentes curriculares do curso de licenciatura. A partir dos dados apresentados pode-se afirmar que esta relação é sugerida visto a organização da categoria "Outros" no Quadro 1. Quanto a abordagem das Geometrias Não Euclidianas que colaboram com o entendimento do desenvolvimento da Matemática, esta também é constatada, porém, em menor ênfase.

Ao se tratar de componentes curriculares específicos de GE, verifica-se que esta recebe menos ênfase quando comparada as Geometrias Plana e Analítica. Além disso, foram identificados cursos que não possuem componentes específicos de GE, corroborando com os resultados de Lovis e Franco (2015).

Os componentes curriculares, em sua maioria, enfatizam a abordagem axiomática, a qual Pavanello e Andrade (2002) referem ser importante. No entanto, é relevante, mesmo que os componentes curriculares sejam específicos da Matemática, realizar a relação com os conceitos/conteúdos abordados na Educação Básica, pois trata-se de cursos de licenciatura. Contudo, o tipo de abordagem enfatizada e o ementário dos componentes permitem ponderar que esta ação não ocorre.

Buscando pela compreensão dos estudantes a respeito dos conceitos/conteúdos abordados, os PCC mencionam a visualização. No entanto, não se pode afirmar que o uso desse termo traz o entendimento de que a visualização é uma atividade semiótica essencial ao desenvolvimento do raciocínio geométrico, conforme sugere Duval (2004; 2011).

Em relação ao uso de diferentes representações de objetos matemáticos, os PPC expõem, nos objetivos dos componentes curriculares, a necessidade de representar os objetos geométricos por meio de distintos recursos, por exemplo, software e materiais manipuláveis. Mas, a mobilização e articulação de diferentes representações matemáticas, em particular, as representações figural e discursiva (língua natural e linguagem formal), essenciais na resolução de problemas geométricos, não são enfatizadas (DUVAL, 2004; 
2011).

Esta investigação foi produzida a partir de dados pertencentes a uma pesquisa vinculada ao Programa de Pós-Graduação e Ensino de Física da Universidade Federal de Santa Maria/RS, elaborada por uma das autoras do artigo. Em virtude disso, esta pesquisa terá continuidade por meio da exploração e verificação das obras mais utilizadas nos componentes curriculares que abordam a GE em instituições federais que ofertam cursos de Matemática Licenciatura.

Ainda é cabível ressaltar que o presente trabalho foi realizado com o apoio da Coordenação de Aperfeiçoamento de Pessoal de Nível Superior Brasil (CAPES) - Código de Financiamento 001.

\section{Referências}

BARDIN, L. Análise de Conteúdo. São Paulo: Edições 70, 2011.

BRASIL. Base Nacional Comum Curricular. Brasília: Ministério da Educação, Secretaria de Educação Básica, Brasília: MEC/ 2018.

BRASIL. Parecer CNE/CP 9/2001. Diretrizes Curriculares Nacionais para a Formação de Professores da Educação Básica, em nível superior, curso de licenciatura, de graduação plena. Conselho Nacional de Educação, Brasília: MEC/ 2002a.

BRASIL. PCN+Ensino Médio - Orientações Educacionais Complementares aos Parâmetros Curriculares Nacionais. Ciência da Natureza, Matemática e Tecnologia. Brasília: MEC/Semtec, 2002b.

BONINI, A.; DRUCK, I. F.; BARRA, E. D. O. Direitos à aprendizagem e ao desenvolvimento na educação básica: subsídios ao currículo nacional. Disponível em < https://acervodigital.ufpr.br/handle/1884/55911> Acesso em jul. 2019.

BORBA, M. C. A pesquisa qualitativa em educação matemática. In: $27^{\mathrm{a}}$ reunião anual da Anped. Caxambu, MG. 2004. Anais... Disponível em https://www.researchgate.net/publication/228889292. Acesso em: out. de 2019.

DUVAL, R. Semiosis y Pensamiento Humano. Registres sémiotiques et apprentissages intellectuels: Santiago de Calai, Colômbia, 2004.

DUVAL, R. Ver e ensinar matemática de outra forma: entrar no modo matemático de pensar: os registros de representação semióticas. Org.: Tânia M. M. Campos. $1^{\circ}$ ed. São Paulo: PROEM, 2011. 
FIORENTINI, D. A Formação Matemática e Didatico-Pedagógica nas Disciplinas da Licenciatura em Matemática. Revista de Educação. Campinas, n. 8 p. 107-115, 2005.

FLORES, C. R. Geometria e Visualização: Desenvolvendo a competência heurística através da reconfiguração. Dissertção (Mestrado em Educação) Universidade Federal de Santa Catarina, Florianópolis, 1997.

LOVIS, K. A.; FRANCO, V. S. As concepções de geometrias não euclidianas de um grupo de professores de matemática da educação básica. Bolema, Rio Claro (SP), v. $29, \quad$ n. $51, \quad$ p. 369-388, 2015. Disponível em: < http://www.scielo.br/pdf/bolema/v29n51/1980-4415-bolema-29-51-0369.pdf > Acesso em abr. 2019.

PAVANELLO, R. M.; ANDRADE, R. Nozaki G. Formar professores para ensinar Geometria: um desafio para as licenciaturas em matemática. Educação Matemática em Revista. São Paulo, a. 9, n. 11, edição especial, 2002.

PAVANELLO, R. M. O abandono do ensino da Geometria no Brasil: causas e consequências. Revista Zetetiké. Campinas: UNICAMP, Ano 1, n. 1, 1993.

PIRES, C. M. C. Reflexões sobre os cursos de Licenciatura em Matemática, tomando como referência as orientações propostas nas Diretrizes Curriculares Nacionais para a formação de professores da Educação Básica. Educação Matemática em Revista, São Paulo, v. 11A, p.44-56, 2002.

SANCHEZ, J. B. dos. Mapeamento da pesquisa acadêmica brasileira sobre Geometria Espacial: período 2007 a 2017. Dissertação (Mestrado em Educação Matemática) Pontifícia Universidade Católica de São Paulo, São Paulo, 2018.

SANTOS, L.; OLIVEIRA, H. O ensino e a aprendizagem da geometria: perspetivas curriculares. In: Livro de Atas do EIEM 2017, Encontro de Investigação em Educação Matemática, 2017.

SENA, R. M; DORNELES, B. V. Ensino de Geometria: Rumos da pesquisa (19912011). Revemat, Florianópolis, v. 08, n. 1, p. 138-155, 2013.

SOCIEDADE BRASILEIRA DE EDUCAÇÃO MATEMÁTICA-SBEM. A formação do professor de matemática no curso de licenciatura: reflexões produzidas pela comissão paritária SBEM/SBM. Brasília: Sociedade Brasileirade Educação Matemática, Boletim SBEM, n. 21, fevereiro, p. 1-42, 2013.

SOCIEDADE BRASILEIRA DE EDUCAÇÃO MATEMÁTICA-SBEM. Subsídios para a Discussão de Propostas para os Cursos de Licenciatura em Matemática: Uma contribuição da Sociedade Brasileira de Educação Matemática. São Paulo: SBEM, 2003a. Documento produzido pelo I Seminário Nacional "Construindo propostas para os Cursos de Licenciatura em Matemática”, Salvador, 2003.

Recebido em novembro de 2019.

Aprovado em fevereiro de 2020. 